\title{
Miller-fisher syndrome on the borders of guillain-barre syndrome: about one case and review of literature
}

\author{
Lompo Djingri Labodi' ${ }^{*}$, Maitrot Adrien², Aubertin Anne², Khatib Muhammad², Decombes René2 and Billaud Bernard² \\ ${ }^{1} \mathrm{CHU}$ de Tingandogo, Unité de Formation et de Recherches des Sciences de la Santé, Université Ouaga I-Pr Joseph Ki-Zerbo, Ouagadougou, Burkina Faso \\ ${ }^{2}$ Service de neurologie, Centre Hospitalier de Troyes, 101 avenue Anatole France, 10000 Troyes, France
}

\begin{abstract}
Miller-Fisher syndrome combines the clinical trial, ophthalmoplegia, ataxia, and diffuse osteotendinous areflexia. It is a variant of Guillain-Barré syndrome, from which it differs by the positivity of anti-GQIb antibodies in the serum. Its clinical evolution is most often favorable. In addition to the classical form, exceptional clinical forms, either incomplete or extended to the confines of the SGB are also described. We thus describe a case of extensive SMF, overlapping with the SGB, associating in addition to the classical triad, bulbar, facial and dysautonomic involvement, of rapidly favorable evolution after a polyvalent immunoglobulin treatment in intravenous, in a man French 47-year-old.
\end{abstract}

\section{Introduction}

Miller-Fisher syndrome (MFS) with an incidence of 0.04 to $0.18 / 100,000$ and a prevalence of $6.6 \%$ of cases of Guillain-Barré syndrome (GBS) [1,2], is a rare affection in Europe, but relatively more common in East Asia, where it accounts for about $18 \%$ of GBS cases in Hong Kong [3]. This condition, first described by Fisher in 1956, is characterized by the triad: ophthalmoplegia, areflexia, ataxia, associated with a usual positivity of antibodies (Ab) anti gangliosides GQ1b type in serum. It is in fact a particular form of GBS: usual occurrence after infectious episode, frequent albumino-cytological dissociation of the cerebrospinal fluid (CSF), clinical recovery after an ascending phase, then plateau, abnormalities of the nerve conduction. In addition to the classical form, the spectrum of MFS includes incomplete forms and extensive forms, with additional clinical features such as the Bickerstaff rhombencephalitis phenotype or symptomatology suggesting overlap with classical GBS or its other variants $[4,5]$. We describe a case of extensive MFS, overlapping with GBS, associating lesions, bulbar, facial and dysautonomic, rapidly favorable evolution after a cure of polyvalent immunoglobulin intravenous (IGIV), in a French man of 47 years, hospitalized, then externally followed for 3 months, in the Department of Neurology of the Hospital Center (HC) of Troyes, France.

\section{Clinical observation}

A 47-year-old French man, a mechanic by profession, with no particular pathological history, was hospitalized in the neurology department of the HC in Troyes, France, from 13 to 30/10/2013, for the progressive onset over 2 days, dysphonia (nasal voice) with dysphagia, paresthesia (tingling) of both hands, binocular horizontal diplopia, without temporal variability, preceded 3 weeks earlier by an episode of acute nasopharyngitis. The initial clinical examination found a complete, predominantly horizontal ophthalmoplegia associated with a bilateral ptosis predominant on the right, a static \& kinetic ataxia not increased by the closure of the eyes, a diffuse osteotendinous areflexia, an involvement of the bulbar cranial nerves (IX \& X) paresis of the soft palate, abolition of the nauseated reflex, dysphonia (nasal voice) and dysphagia and finally a bilateral peripheral facial paresis. At this stage,
MFS, acute rhombencephalitis, vertebrobasilar infarction, or other brainstem injury were discussed. Cerebral CT and then brain MRI returned normal ; as well as the lumbar puncture (LP) with cytological and microbiological study of the CSF, allowing to eliminate the different diagnostic hypotheses, except the MFS. Demonstration of an albuminocytological dissociation with proteinase increased to $0.71 \mathrm{~g} / \mathrm{l}$ and normal cytology, associated with a positivity of the anti-ganglioside antibodies type $1 \mathrm{~b}$ (antiGQ1b Ab), type IgG $(+++)$ and antiGT1a $\mathrm{Ab}$, type $\operatorname{IgG}(+++)$ in serum, allowed to establish the diagnosis of MFS. The usual biological assessment (blood count-platelet count, blood crase, blood ionogram, renal and hepatic functions, ...), thyroid assessment returned normal.

Electroneuromyographic examination (ENMG) found a homogeneous and marked decrease in the amplitude of the sensory potentials and an increase in the latency of the $\mathrm{F}$ waves of nerves, in the 4 limbs, reflecting a heterogeneous slowing of the proximal motor conduction. On the other hand, we noted a preservation of motor conduction velocities (VCM), sensory conduction velocities (VCS), motor distal latencies (LDM) and the amplitude of motor potentials.

A non-exhaustive infectious etiological blood test was negative: viral serologies (CMV, EBV, rubella, HSV $1 \& 2, \mathrm{VZV}$, hepatitis A, B, C, HIV); toxoplasmosis serology; IDR tuberculin. An exhaustive blood self-immunity assessment returned negative, except for the anti-GQ1b and GTD1a Ab positivity. The cryoglobulinemia test returned negative

Correspondence to: Lompo Djingri Labodi, CHU de Tingandogo, Unité de Formation et de Recherches des Sciences de la Santé, Université Ouaga I-Pr Joseph Ki-Zerbo, Ouagadougou Burkina Faso, Tel: +226 702398 34; E-mail: labodilompo@yahoofr

Key words: ophthalmoplegia-areflexia-ataxia ; anti-GQ1b antibodies ; bulbar facial and dysautonomic involvement

Received: January 04, 2018; Accepted: January 22, 2018; Published: January 25, 2018 


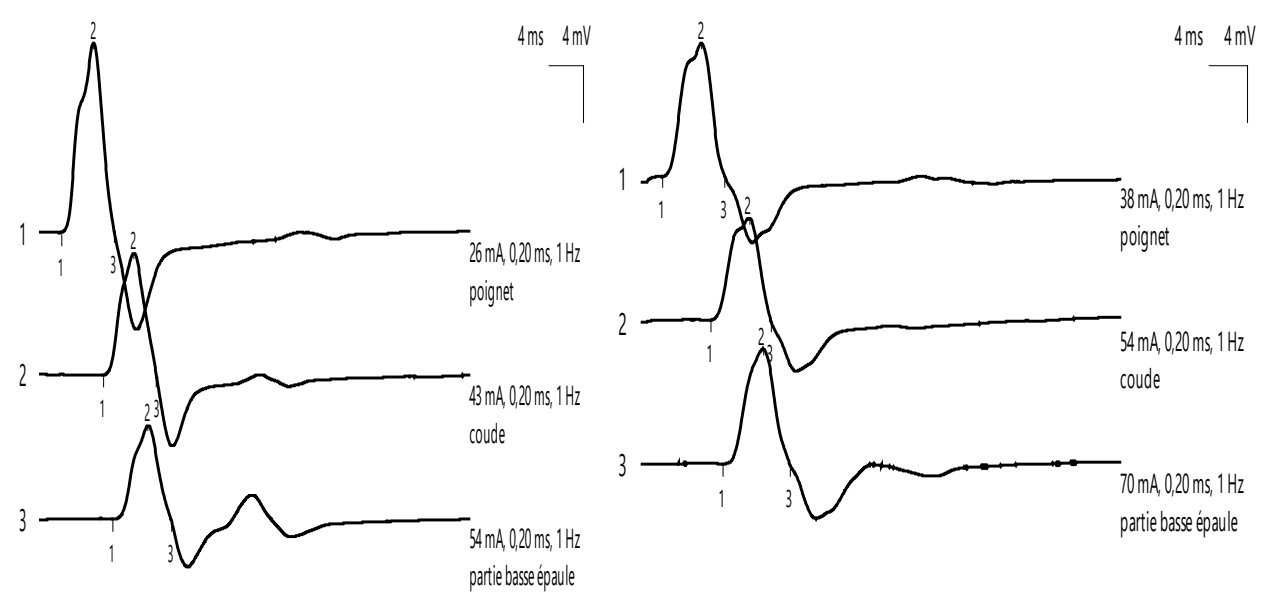

Figure 1. Motor Conduction Velocity. Abductor $5^{\text {th }}$ finger, Cubital C8 T1, Right and left
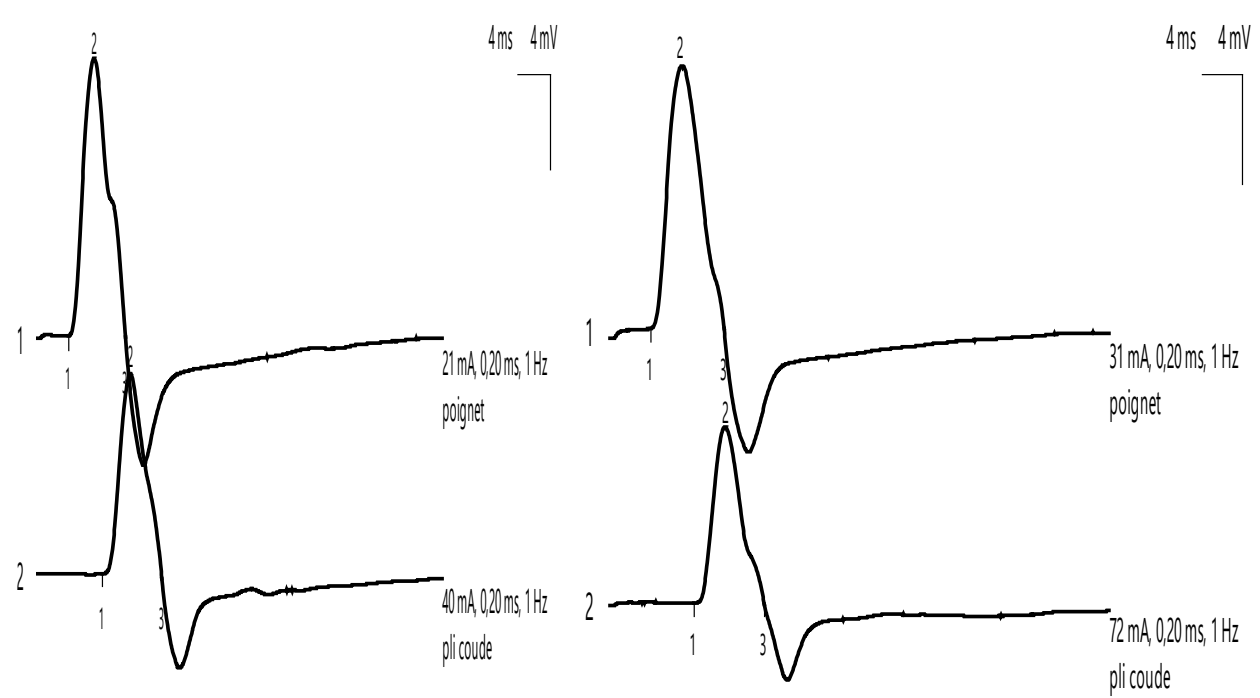

Figure 2. Motor Conduction Velocity. Short abductor I, MEDIAN C6 T1, Right and left

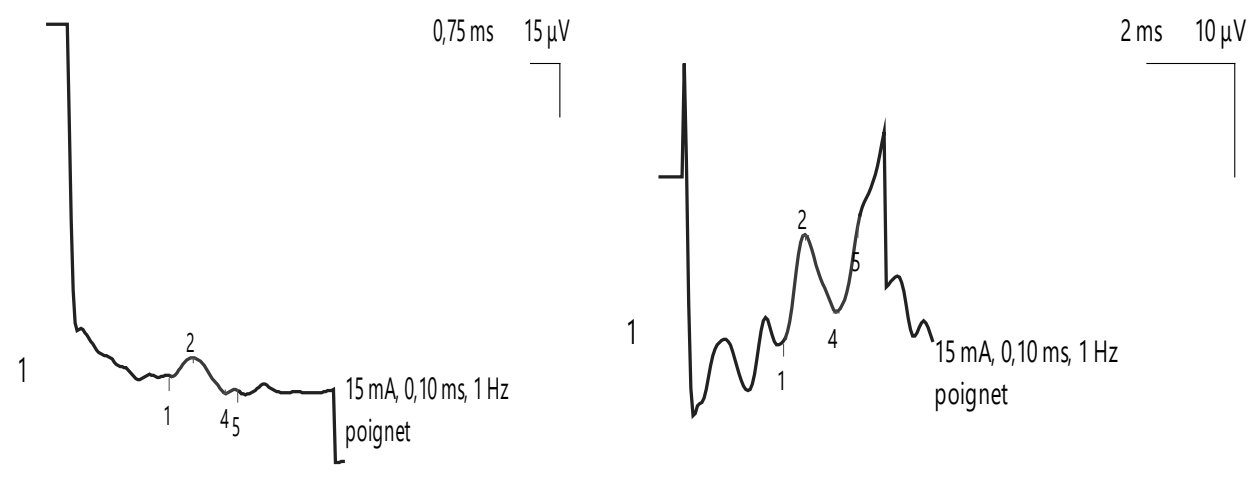

Figure 3. Sensory Conduction Velocity. Antidromic, MEDIAN, Right and left 


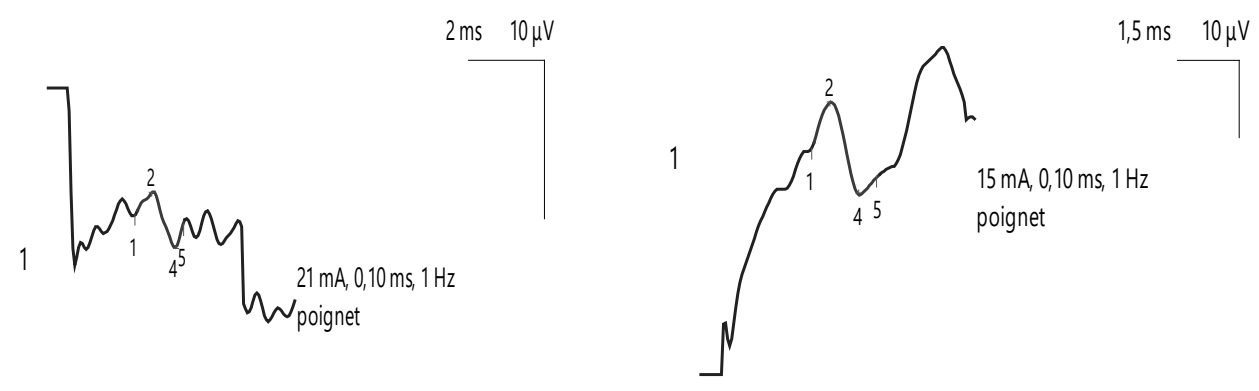

Figure 4. Sensory Conduction Velocity. Antidromic, Cubital, $5^{\text {th }}$ finger, Right and left
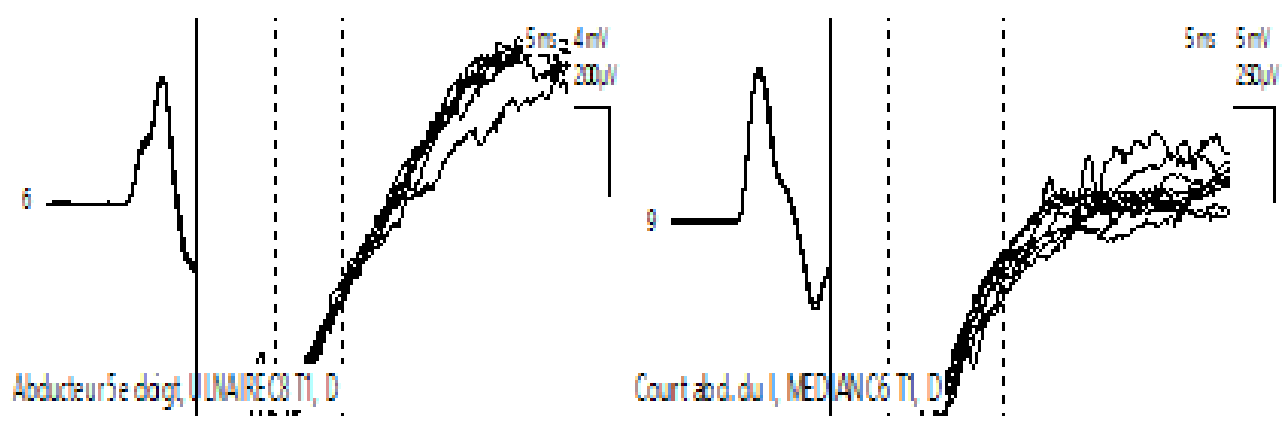

Figure 5. F wave. Abductor $5^{\text {th }}$ finger, F wave. Short abductor first finger, MEDIAN C6 T1, Right Cubital C8 T1, Right

Table 1. Motor nerve conduction parameters

\begin{tabular}{|c|c|c|c|c|c|c|}
\hline & Right median & Left median & Right cubital & Left cubital & Right fibular & Left fibular \\
\hline $\begin{array}{c}\text { Motor conduction } \\
\text { velocity }(\mathrm{MCV})(\mathrm{m} / \mathrm{s})\end{array}$ & 60,2 (normal) & 54,5 (normal) & $55,1 / 68,3$ (normal) & $\begin{array}{r}56,0 / 69,2 \\
\text { (normal) }\end{array}$ & $\begin{array}{r}45,4 / 49,5 \\
\text { (normal) }\end{array}$ & $\begin{array}{c}46,5 / 44,3 \\
\text { (normal) }\end{array}$ \\
\hline Distal latencies (ms) & $\begin{array}{c}3,0 \\
\text { (normal) }\end{array}$ & $\begin{array}{c}3,1 \\
\text { (normal) }\end{array}$ & 2,5 (normal) & $\begin{array}{c}2,2 \\
\text { (normal) }\end{array}$ & $\begin{array}{c}5,3 \\
\text { (normal) }\end{array}$ & $\begin{array}{c}6,0 \\
\text { (normal) }\end{array}$ \\
\hline F waves latencies (ms) & 30,5 (increased) & $\begin{array}{c}30,6 \\
\text { (increased) }\end{array}$ & 38,5 (increased) & $\begin{array}{c}35,7 \\
\text { (increased) }\end{array}$ & 52,6 (increased) & $\begin{array}{c}56,4 \\
\text { (inceased) }\end{array}$ \\
\hline $\begin{array}{c}\text { Amplitudes of motor } \\
\text { potentiels (AMP) (mV) }\end{array}$ & $11,7 / 8,4$ (normal) & $\begin{array}{c}9,6 / 6,4 \\
\text { (normal) }\end{array}$ & $13,3 / 8,5 / 6,5$ (normal) & $\begin{array}{l}9,3 / 7,1 / 8 \\
\text { (normal) }\end{array}$ & $\begin{array}{c}4,2 / 3,7 / 3,5 \\
\text { (normal) }\end{array}$ & $\begin{array}{c}3,8 / 3,6 / 3,6 \\
\text { (normal) }\end{array}$ \\
\hline
\end{tabular}

Table 2. Sensitive nerve conduction parameters

\begin{tabular}{|c|c|c|c|c|c|c|c|c|}
\hline & Right median & Left median & Right cubital & Left cubital & \begin{tabular}{|c|} 
Right \\
musculocutaneous
\end{tabular} & \begin{tabular}{|c|} 
Left \\
musculocutaneous
\end{tabular} & Right sural & Left sural \\
\hline $\begin{array}{c}\text { Sensi tive } \\
\text { conduction velocity } \\
(\mathrm{SCV})(\mathrm{m} / \mathrm{s})\end{array}$ & $\begin{array}{c}44,8 \\
\text { (normal) }\end{array}$ & 59,4 (normal) & 45,7 (normal) & 55,3 (normal) & $\begin{array}{c}49,5 \\
\text { (normal) }\end{array}$ & 50,2 (normal) & 51,9 (normal) & 55,3 (normal) \\
\hline Amplitudes (UV) & $\begin{array}{c}5,0 \\
\text { (decreased) }\end{array}$ & $\begin{array}{c}9,4 \\
\text { (decreased) }\end{array}$ & $\begin{array}{c}1,4 \\
\text { (very diminished) }\end{array}$ & $\begin{array}{c}4,9 \\
\text { (very dilinished) }\end{array}$ & $\begin{array}{c}2,3 \\
\text { (very diminished) }\end{array}$ & $\begin{array}{c}1,3 \\
\text { (very diminished) }\end{array}$ & $\begin{array}{c}1,8 \\
\text { (very diminished) }\end{array}$ & $\begin{array}{c}1,6 \\
\text { (very diminished) }\end{array}$ \\
\hline
\end{tabular}

and the B6 and B12 vitaminemia test returned normal.

The immediate evolution is marked by an increase of ataxia with standing and walking becoming impossible, an increase of ophthalmoplegia, dysphagia become major with fake food routes \& liquid nasal reflux, ... and especially the appearance of dysautonomia with hemodynamic instability type (blood pressure fluctuations and bradypnea access). On day 10 of hospitalization, the patient was able to benefit from a cure of IGIV, followed by a rapidly favorable clinical evolution, noted as early as day15, allowing from day18 of hospitalization, the transfer of the patient towards a center of functional rehabilitation, for the continuation of a motor physiotherapy. Thus, at 8 weeks post-hospitalization, there was a complete recovery with restitution ad integrum with resumption of socio-professional activities.

\section{Discussion}

The MFS spectrum includes the classical form, incomplete forms (acute ophthalmoparesis, acute ataxic sensory neuropathy, acute ptosis, acute paralytic mydriasis) and extensive forms, with additional clinical features such as the Bickerstaff rhombencephalitis phenotype or symptoms suggestive of overlap with classical GBS or other variants: pharyngo-cervico-brachial involvement, acute glosso-pharyngolaryngeal weakness, paraparetic GBS, facial diplegia with paresthesia [4].

Patients with the typical form of MFS present the classic triad ophthalmoplegia, ataxia, hypo- or areflexia; those with REB, which is the central form of MFS, present impaired alertness and / or osteotendinous hyperreflexia [6]. Incomplete forms of MFS include acute ataxic neuropathy, which can be diagnosed in the absence of ophthalmoplegia, and acute ophthalmoparesis, which can be diagnosed in the absence of ataxia. The very incomplete forms of MFS have only isolated ptosis or isolated mydriasis. The diagnosis of incomplete REB, known as acute ataxic hypnotism, may be carried out in patients with signs of ataxia and hyper-somnolence in the absence of ophthalmoplegia.. The presence of IgG anti-GQ1b or anti-GD1b antibodies confirms the clinical diagnosis of these MFS subtypes $[4,6]$. 
Several overlapping syndromes between GBS-MFS and their respective subtypes are reported: pharyngo-cervico-brachial weakness with ophthalmoplegia, pharyngo-cervico-brachial weakness with ophthalmoplegia and additional ataxia in the absence of tetraparesis. But, the involvement of the cranial nerves seems to be the most frequent in the forms of MFS-GBS overlap: facial nerve in 30 to $50 \%$ of cases $[2,7,8]$, bulbar cranial nerves, glossopharyngeal (IX), wave ( $\mathrm{X}$ ), large hypoglossus (XII), responsible for disorders of swallowing and dysphonia, in $13 \%$ of cases $[2,7,9]$. Cases of MFS with optic neuropathy (10), quadriplegia, respiratory disease or dysautonomic manifestations (5) are exceptional. Our case included, in addition to the classic MFS triad, facial, bulbar and dysautonomic impairment. According to some authors, neuropathies, acute sensory small-fiber, acute sensory and autonomic and acute pandysautonomy probably represent postinfectious autoimmune diseases similar to those of GBS [11-13].

ENMG of MFS found a sensory axon neuropathy, usually characterized by an isolated alteration or even absence of sensory potentials, sometimes associated with a discrete slowing of Sensitive conduction velocity (SCV) $[4,14,15]$. Motor conduction abnormalities appear in the second plane: moderate and delayed deceleration of motor conduction velocity (MCV), lengthening latencies of $F$ waves or alteration of motor potentials $[5,14]$. In our patient, we found an alteration of the sensory potentials associated with an elongation of the latencies of the $\mathrm{F}$ waves, of heterogeneous distribution. However, the rare anatomo-pathological data have rather demonstrated a demyelination of peripheral sensory fibers [16]

The study of CSF found the classic albumino-cytological dissociation, that is to say, a moderately high CSF protein without cellular reaction, as in our patient. However, pleocytosis is sometimes described [17].

Anti GQ1b abs are a specific marker for MFS and Bickerstaff acute rhombencephalitis: they are positive in 83 to $89 \%$ of MFS cases, $68 \%$ of Bickerstaff rhombencephalitis cases and only in 7\% of cases of GBS with oculomotor involvement $[17,18]$. They are thought to be the cause of ophthalmoplegia and acute ataxia $[19,20]$. Their presence in the serum is an essential diagnostic criterion of the MFS. They often coexist with anti GT1a abs, due to cross-reactivity; case of our patient. The rare cases of seronegative MFS are related to a method of detection of insufficient sensitivity or different immunological mechanism (other antigen) [21]. Rare cases of non-ophtalmoplegic anti-GQ1b abs have also been reported: MFS with acute oropharyngeal palsy \pm ataxia [22], GBS beginning with bulbar palsy [23], some ataxic SGB forms [24].

The ganglioside GQ1b is strongly expressed in oculomotor nerves, in particular trochlear and abducens nerves, optic nerves, as well as neuromuscular junctions $[19,20]$. In addition, GQ1b is possibly expressed in the reticular formation, and anti-GQ1b Ab could therefore explain the impairment of alertness observed in patients with Bickerstaff rhombencephalitis [18]. Acute ophthalmoparesis is also associated with the presence of anti-GQ1b Ab, and some patients later develop bilateral facial or bulbar weakness [24]. Isolated ptosis and mydriasis, caused by weakness of the upper eyelid levator and iris sphincter muscles, also reported in association with antiGQ1b Ab, represent for some authors a very incomplete clinical form of SMF (25\%).

Some authors $[21,26$ have thus hypothesized an antiGQ1b Ab syndrome including MFS, Bickerstaff acute rhombencephalitis and isolated acute ophthalmoplegia. Note, however, the description of a particular case of zosterian rhombencephalitis with ophthalmoplegia associated with a high level of IgG anti GQ1b [4]
Like the GBS, the MFS is frequently preceded by an infection. These may include viral infections (CMV, EBV, VZV, HIV, hepatitis, mumps), bacterial infections (C. jejuni, M. pneumoniae, Q fever, $\mathrm{H}$. influenzae, Pasteurella, H. pylori), mycoses (aspergillosis) [1, 7], most recently the H1N1 virus [27]. C. jejuni strains were thus isolated from MFS cases bearing epitopes binding anti-GQ1b Ab, which favors cross-immunization between GQ1b ganglioside antigens and C. jejuni antigens [24].

\section{Conclusion}

MFS, a variant of GBS, is a rare condition, most often following an infection of the respiratory upper voices or digestive tract. It combines the clinical triad, acute ophthalmoplegia, ataxia, hypo or areflexia; frequent alteration of sensory potentials and sometimes prolongation of F-wave latencies to EMG; an albumino-cytological dissociation of the CSF and an anti-GQ1b Abs type IgG positivity in the serum. Evolution is usually favorable. Rare, extensive clinical forms at the borders of GBS, sometimes serious, are sometimes described. Our study thus reports a case of extensive SMF, associating in addition an involvement of bulbar cranial nerves, facial and autonomic dysfunction.

\section{References}

1. Guilloton L, Camarasa C, Agard E, Tondeur G, Dot C, et al., (2014) Ataxie avec ophtalmoplégie: syndrome de Miller-Fisher avec positivité des anticorps anti-GQ1b. Journal Français d'Ophtalmologie 37: 89-92.

2. Arányi Z, Kovács T, Sipos I, Bereczki D (2012). Miller Fisher syndrome: brief overview and update with a focus on electrophysiological findings. European journal of neurology 19: 15 [Crossref]

3. Yuan CL, Wang YJ, Tsai CP (2000) Miller Fisher syndrome: a hospital-based retrospective study. European neurology $44: 79-85$ [Crossref]

4. Wakerley BR, Uncini A, Yuki N (2014) Guillain-Barre and Miller Fisher syndromes [mdash] new diagnostic classification. Nature Reviews Neurology 10: 537-544 [Crossref]

5. Gory M, Megarbane B, Marchal P, Thalamon C, D Allest A M, et al., (2001) Syndrome de Miller-Fisher avec tetraplegie, atteinte respiratoire et dysautonomie. La Revue de médecine interne 22: 760-761

6. Odaka M (2003) Bickerstaff's brainstem encephalitis: clinical features of 62 cases and a subgroup associated with Guillain-Barré syndrome. Brain 126: 2279-2290. [Crossref]

7. Lo YL. Clinical and immunological spectrum of the miller fisher syndrome. Muscle \& nerve 36.5 (2007): 615-627. [Crossref]

8. Berlit P, Rakicky J (1992) The Miller Fisher Syndrome: Review of the Literature. Journal of Neuro-Ophthalmology 12: 57-63 [Crossref]

9. Laplatte G, Bouterra C, Itani A, Kuteifan K, Gutbub AM (2000) Syndrome de MillerFischer, anticorps anti-GQ 1b et Campylobacter jejuni: à l'occasion d'une observation. Reanimation Urgences 9: 224-226.

10. Colding-Jørgensen E, Vissing J (2001) Visual impairment in anti-GQ1b positive Miller Fisher syndrome. Acta neurologica scandinavica 103: 259-260. [Crossref]

11. Koike, H (2010) Clinicopathological features of acute autonomic and sensory neuropathy. Brain $133: 2881-2896$. [Crossref]

12. Koike, $H$ (2012) The spectrum of clinicopathological features in pure autonomic neuropathy. J Neurol 259: 2067-2075 [Crossref]

13. Ohyama, K (2013) Autonomic manifestations in acute sensory ataxic neuropathy: a case report. Auton. Neurosci 179: 155-158.

14. Durand MC, Lofaso F, Lefaucheur JP, Chevret S, Gajdos P, et al., (2003) Electrophysiology to predict mechanical ventilation in Guillain-Barré syndrome. European journal of neurology 10: 39-44. [Crossref]

15. Azulay JP, Verschueren A, Attarian S, Pouget J (2002) Le syndrome de Guillain-Barré et ses frontières. Revue neurologique 158: 6S21-6S26.

16. Dehaene I, Martin JJ, Geens K, Cras P (1986) Guillain-Barré syndrome with ophthalmoplegia Clinicopathologic study of the central and peripheral nervous systems, including the oculomotor nerves. Neurology 36: 851-851. [Crossref] 
17. Yuki N (2009) Fisher syndrome and Bickerstaff brainstem encephalitis (FisherBickerstaff syndrome). Journal of neuroimmunology 215: 1-9 [Crossref]

18. Ito, M (2008) Bickerstaff's brainstem encephalitis and Fisher syndrome form a continuous spectrum: clinical analysis of 581 cases. J Neurol 255: 674-682. [Crossref]

19. Liu JX, Willison HJ, Pedrosa-Domellof F (2009) Immunolocalization of GQ1b and related gangliosides in human extraocular neuromuscular junctions and muscle spindles. Invest. Ophthalmol Vis. Sci 50 : 3226-3232. [Crossref]

20. Chiba A, Kusunoki S, Obata H, Machinami R, Kanazawa I (1993) Serum anti-GQ1b IgG antibody is associated with ophthalmoplegia in Miller Fisher syndrome and Guillain-Barré syndrome Clinical and immunohistochemical studies. Neurology 43: 1911-1911. [Crossref]

21. Masson C (2001) Le syndrome antiGQ1b.Presse médicale

22. Kamakura L, Kanzaki M, Kaida KI, Ueda M, Morita D et al., (2008) Ganglioside complexes containing GQ1b as targets in Miller Fisher and Guillain-Barré syndromes. Journal of Neurology, Neurosurgery \& Psychiatry 79: 1148-1152 [Crossref]
23. Koga M, Willison HJ, O'Hanlon GM (1999) The immunopathogenesis of Miller Fisher syndrome. Journal of neuro immunology 100: 3-12 [Crossref]

24. Yuki N, Susuki K, Hirata K (2000) Ataxic Guillain-Barré syndrome with anti-GQ1b antibody: relation to Miller Fisher syndrome. Neurology 54: 1851-1853. [Crossref]

25. Jindal G, Parmar VR, Gupta VK (2009) Isolated ptosis as acute ophthalmoplegia without ataxia, positive for anti-GQ1b immunoglobulin G. Pediatr. Neurol 41: 451452. [Crossref]

26. Hamaguchi T, Yamaguchi K, Komai K, Yamada M et al., (2003). Recurrent anti-GQ1b IgG antibody syndrome showing different phenotypes in different periods. Journal of Neurology, Neurosurgery \& Psychiatry 74: 1350-1350. [Crossref]

27. Zoulillou A, Larabi K, Lucchini-Lecomte MJ, Fanton Y, Tafani B (2012) Syndrome de Miller-Fisher et Influenza A. Revue neurologique 168: 465-466.

Copyright: $@ 2018$ Labodi LD. This is an open-access article distributed under the terms of the Creative Commons Attribution License, which permits unrestricted use, distribution, and reproduction in any medium, provided the original author and source are credited. 